\title{
Patterns and determinants of COPD-related healthcare utilization by severity of airway obstruction in Korea
}

Kyungsoo Chung ${ }^{1}$, Kyungjoo Kim² ${ }^{2}$ Jiye Jung ${ }^{1}$, Kyungwon $\mathrm{Oh}^{3}$, Yeonmok $\mathrm{Oh}^{4}$, Sekyu Kim${ }^{1}$, Jinhee $\mathrm{Kim}^{5^{*}}$ and Youngsam Kim ${ }^{1 *}$

\begin{abstract}
Background: We investigated patients with chronic obstructive pulmonary disease (COPD) to analyze patterns and identify determinants of healthcare use, according to the severity of airflow obstruction. We used retrospective cohort data from a combination of the $4^{\text {th }}$ Korea National Health and Nutritional Examination Survey (KNHANES) and Korean National Health Insurance $(\mathrm{NHI})$ claims.
\end{abstract}

Methods: Demographic and medical claims data were retrospectively analyzed from the $4^{\text {th }}$ KNHANES along with $\mathrm{NHI}$ claims. Eligible patients were aged $\geq 40$ years, who underwent complete pulmonary function tests (PFTs), and had at least one inpatient or outpatient claim coded as COPD between January 1, 2007 and December 31, 2010.

Results: Among 6,663 eligible participants, 897 (13.5\%) had airway obstruction. Self-reported physician-diagnosed COPD comprised only $3 \%$, and there were 870 undiagnosed COPD patients (97\%). Self-reported physiciandiagnosed asthma made up 3.7\%. Of the 897 respondents, 244 (27.2\%) used COPD-related healthcare services. The frequency of healthcare visits increased with increasing severity of airway obstruction. After a 3-year follow-up period, 646 (74.2\% of those initially undiagnosed) remained undiagnosed and only 224 (25.8\%) were diagnosed and treated for COPD. Only $27.5 \%$ of the 244 participants with airway obstruction who used COPD-related healthcare underwent PFTs during the study period. The percentage of prescribed medications associated with COPD increased in accordance with the severity of the COPD. Inhaled long-acting anticholinergics were prescribed for $10.9 \%$ of patients with moderate airway obstruction and for $52.4 \%$ of patients with severe obstruction. Inhaled long-acting $\beta$-agonists combined with corticosteroids were prescribed for $50 \%$ of patients with severe airway obstruction. Conversely, $44.6 \%$ of healthcare users were prescribed oral theophylline for COPD treatment, and 21.7\% were also prescribed an oral corticosteroid. The determinants of COPD-associated healthcare use in respondents with obstructive lung disease were advanced age, severe airflow limitation, presence of comorbidities, and self-reported physician diagnosis of COPD.

Conclusions: This study ascertained marked underdiagnosed COPD. Although the percentage of prescribed medication used to treat COPD increased with the severity of the COPD, medications primarily prescribed such as oral theophylline or oral corticosteroids are inappropriate for first-line COPD treatment.

Keywords: Chronic obstructive lung disease, Healthcare use, Korean National Health and Nutritional Examination Survey, National health insurance claims

\footnotetext{
* Correspondence: jinheeara@hanmail.net; ysamkim@yuhs.ac

${ }^{5}$ Department of Nursing, College of Medicine, Chosun University, Gwangju, Republic of Korea

'Division of Pulmonology, Department of Internal Medicine, The Institute of Chest Disease, Severance Hospital, Yonsei University College of Medicine, Seoul, Republic of Korea

Full list of author information is available at the end of the article
}

\section{Biomed Central}

(c) 2014 Chung et al.; licensee BioMed Central Ltd. This is an Open Access article distributed under the terms of the Creative Commons Attribution License (http://creativecommons.org/licenses/by/2.0), which permits unrestricted use, distribution, and reproduction in any medium, provided the original work is properly credited. 


\section{Background}

Chronic obstructive pulmonary disease (COPD) involves progressive, irreversible airflow limitation resulting in disabling respiratory symptoms and devastating comorbidities, all of which place an increasing burden on public healthcare services [1-4]. COPD is the fourth leading cause of death, but the World Health Organization predicts that it will move up to third by 2030. Furthermore, COPD is often underdiagnosed and undertreated [5-9].

An understanding of the patterns of healthcare use is fundamental for the establishment of a healthcare plan geared towards the proper management and treatment of COPD. Data about COPD-related healthcare, such as hospital visits, the use of pulmonary function tests (PFTs), and medications prescribed according to the severity of symptoms, are lacking $[10,11]$. A retrospective cohort was created from the combination of data from the $4^{\text {th }}$ Korea National Health and Nutritional Examination Survey (KNHANES) and Korean National Health Insurance (NHI) claims. The aim of this study was to analyze patterns and identify determinants of healthcare use in COPD patients according to the severity of airflow obstruction.

\section{Methods}

\section{Study population}

Data for this study were obtained from KNHANES IV, in which a stratified, multi-stage, clustered probability design was used to select a representative sample of noninstitutionalized civilians from among the Korean population. KNHANES IV data included information on demographics, smoking status, household income, education, residential area, self-reported physician diagnoses (i.e., COPD, hypertension, ischemic heart disease, osteoporosis, depression, and anemia), and PFTs. However, we inevitably included self-reported physician diagnosis of asthma in our study population because it is not possible to exclude asthma patients using self-reported physician diagnosis criteria. We describe the percentage of asthma patients in our study in Table 1. Spirometry was performed by specially trained technicians according to the 2005 American Thoracic Society/European Respiratory Society recommendations [12]. A total of 12,151 individuals from the KNHANES IV data were older than 40 years of age; however, only $57.1 \%$ of these individuals $(n=6,934)$ underwent complete PFTs. Informed consent was obtained from 96.1\% $(n=6,663)$ of the individuals. Their personal information was successfully combined with records from the computerized Korean NHI claims database between January 1, 2007 and December 31, 2010. The entire population of South Korea has been provided with health coverage since 1989 by the Korean National Health Insurance System, which has managed a computerized database for all medical facilities in South Korea since 1998. The following codes from the Korean version of the International Classification of Diseases, Tenth Revision (ICD-10) were used to identify COPD-related healthcare use: simple and mucopurulent chronic bronchitis (J41), simple chronic bronchitis (J410), mucopurulent chronic bronchitis (J411), mixed simple and mucopurulent chronic bronchitis (J418), unspecified chronic bronchitis (J42), emphysema (J43), MacLeod syndrome (J430), panlobular emphysema (J431), centrilobular emphysema (J432), other emphysema (J438), emphysema, unspecified (J439), other chronic obstructive pulmonary disease (J44), chronic obstructive pulmonary disease with acute lower respiratory infection (J440), chronic obstructive pulmonary disease with acute exacerbation, unspecified (J441), other specified chronic obstructive pulmonary disease (J448), and chronic obstructive pulmonary disease, unspecified (J449). Information on COPDrelated healthcare use from the NHI claims database contained the frequency of healthcare visits, the number of PFTs performed, and any prescribed medications. A total of 897 (13.4\%) of 6,663 eligible individuals demonstrated an obstructive airflow pattern and were included in the final data analysis. Only 244 (27.2\%) of these 897 patients used the healthcare system, and they were assessed based on disease severity (Figure 1). The study protocol was approved by the Public Institutional Review Board (PIRB 11-025-2).

\section{Definition}

\section{COPD and severity of airway obstruction}

Subjects $\geq 40$ years of age with $\mathrm{FEV}_{1} / \mathrm{FVC}<70 \%$ were diagnosed with COPD. The severity of airway obstruction was classified as follows: mild ( $\mathrm{FEV}_{1} \geq 80 \%$ predicted), moderate $\left(50 \leq \mathrm{FEV}_{1}<80 \%\right.$ predicted), and severe $\left(\mathrm{FEV}_{1}<50 \%\right.$ predicted). Additionally, normal lung function was defined as $\mathrm{FEV}_{1} / \mathrm{FVC} \geq 70 \%$ and $\mathrm{FVC} \geq 80 \%$ predicted. Restrictive lung disease was defined as $\mathrm{FEV}_{1} / \mathrm{FVC}>70 \%$ and $\mathrm{FVC}$ $<80 \%$ predicted.

\section{Users and non-users of COPD-related healthcare use}

A user of COPD-related healthcare was defined as a person with a first and second diagnosis of COPD who used any kind of healthcare resource based on insurance claims data. A non-user was defined as a person with a first and second diagnosis of COPD during the follow-up period who did not use healthcare resources.

\section{Variables}

Variables, such as the frequency of healthcare visits, performance of PFTs, and the use of prescribed respiratory medications, were used to investigate patterns of COPDrelated healthcare use (presented as the annual number of visits per person). COPD-related healthcare visits were defined as any kind of visit with first and second diagnosis of COPD. Healthcare visits constituted visits to outpatient clinics, inpatient clinics, intensive care 
Table 1 Baseline characteristics of study population

\begin{tabular}{|c|c|c|c|c|}
\hline Characteristics & 4,895 (73.5) & $871(13.1)$ & $897(13.4)$ & $6,663(100.0)$ \\
\hline \multicolumn{5}{|l|}{ Age group (yr) } \\
\hline $40 \sim 49$ & $1,923(39.3)$ & $171(19.6)$ & $86(9.6)$ & $2,180(32.7)$ \\
\hline $50 \sim 59$ & $1,455(29.7)$ & $222(25.5)$ & $175(19.5)$ & $1,852(27.8)$ \\
\hline $60 \sim 70$ & $1,028(21.0)$ & $259(29.7)$ & $309(34.5)$ & $1,596(24.0)$ \\
\hline $70 \sim$ & $489(10.0)$ & $219(25.1)$ & $327(36.5)$ & $1,035(15.5)$ \\
\hline \multicolumn{5}{|l|}{ Sex } \\
\hline Male & $1,834(37.5)$ & $409(47.0)$ & $628(70.0)$ & $2,871(43.1)$ \\
\hline Female & $3,061(62.5)$ & $462(53.0)$ & $269(30.0)$ & $3,792(56.9)$ \\
\hline \multicolumn{5}{|l|}{ Smoking status* } \\
\hline Never & $3,184(65.4)$ & $505(58.5)$ & $292(32.7)$ & $3,981(60.1)$ \\
\hline Former & $854(17.5)$ & $202(23.4)$ & $299(33.5)$ & $1,355(20.5)$ \\
\hline Current & $830(17.1)$ & $156(18.1)$ & $301(33.7)$ & $1,287(19.4)$ \\
\hline \multicolumn{5}{|l|}{ Region of residence } \\
\hline Urban & $3,514(71.8)$ & $607(69.7)$ & $532(59.3)$ & $4,653(69.8)$ \\
\hline Rural & $1,381(28.2)$ & $264(30.3)$ & $365(40.7)$ & $2,010(30.2)$ \\
\hline \multicolumn{5}{|c|}{ Household income (quartile)* } \\
\hline $1^{\text {st }}$ quartile & $962(20.0)$ & $251(29.6)$ & $347(40.4)$ & $1,560(23.9)$ \\
\hline $2^{\text {nd }}$ quartile & $1,187(24.7)$ & $213(25.1)$ & $217(25.3)$ & $1,617(24.8)$ \\
\hline $3^{\text {rd }}$ quartile & $1,204(25.0)$ & $211(24.9)$ & $152(17.7)$ & $1,567(24.0)$ \\
\hline $4^{\text {th }}$ quartile & $1,456(30.3)$ & $174(20.5)$ & $142(16.6)$ & $1,772(27.2)$ \\
\hline \multicolumn{5}{|l|}{ Education* } \\
\hline$\leq$ Elementary school & $1,663(34.1)$ & $370(42.8)$ & $474(53.4)$ & $2,507(37.8)$ \\
\hline Middle school & $794(16.3)$ & $156(18.1)$ & $159(17.9)$ & $1,109(16.7)$ \\
\hline High school & $1,480(30.4)$ & $204(23.6)$ & $155(17.5)$ & $1,839(27.8)$ \\
\hline$\geq$ College & $938(19.2)$ & $134(15.5)$ & $100(11.3)$ & $1,172(17.7)$ \\
\hline \multicolumn{5}{|l|}{ No. of co-morbidities } \\
\hline 0 & $3,125(63.8)$ & $429(49.3)$ & $477(53.2)$ & $4,031(60.5)$ \\
\hline 1 & $1,231(25.2)$ & $291(33.4)$ & $288(32.1)$ & $1,810(27.2)$ \\
\hline 2 & $430(8.8)$ & $118(13.6)$ & $111(12.4)$ & $659(9.9)$ \\
\hline$\geq 3$ & $109(2.2)$ & $33(3.8)$ & $21(2.3)$ & $163(2.5)$ \\
\hline \multicolumn{5}{|c|}{ No. of healthcare utilization } \\
\hline Yes & $555(11.3)$ & $171(19.6)$ & $244(27.2)$ & $970(14.6)$ \\
\hline No & $4,340(88.7)$ & $700(80.4)$ & $653(72.8)$ & $5,693(85.4)$ \\
\hline \multicolumn{5}{|c|}{ Self-reported physician diagnosis of asthma } \\
\hline Yes & $107(2.2 \%)$ & $34(3.9 \%)$ & $33(3.7 \%)$ & $174(2.6 \%)$ \\
\hline No & $4,788(97.8 \%)$ & 837 (96.1\%) & $864(96.3 \%)$ & 6489 (93.4\%) \\
\hline \multicolumn{5}{|c|}{ Self-reported physician diagnosis of COPD } \\
\hline Yes & $28(0.6)$ & $7(0.8)$ & $27(3.0)$ & $62(0.9)$ \\
\hline No & $4,867(99.4)$ & $864(99.2)$ & $870(97.0)$ & 6,601 (99.1) \\
\hline
\end{tabular}




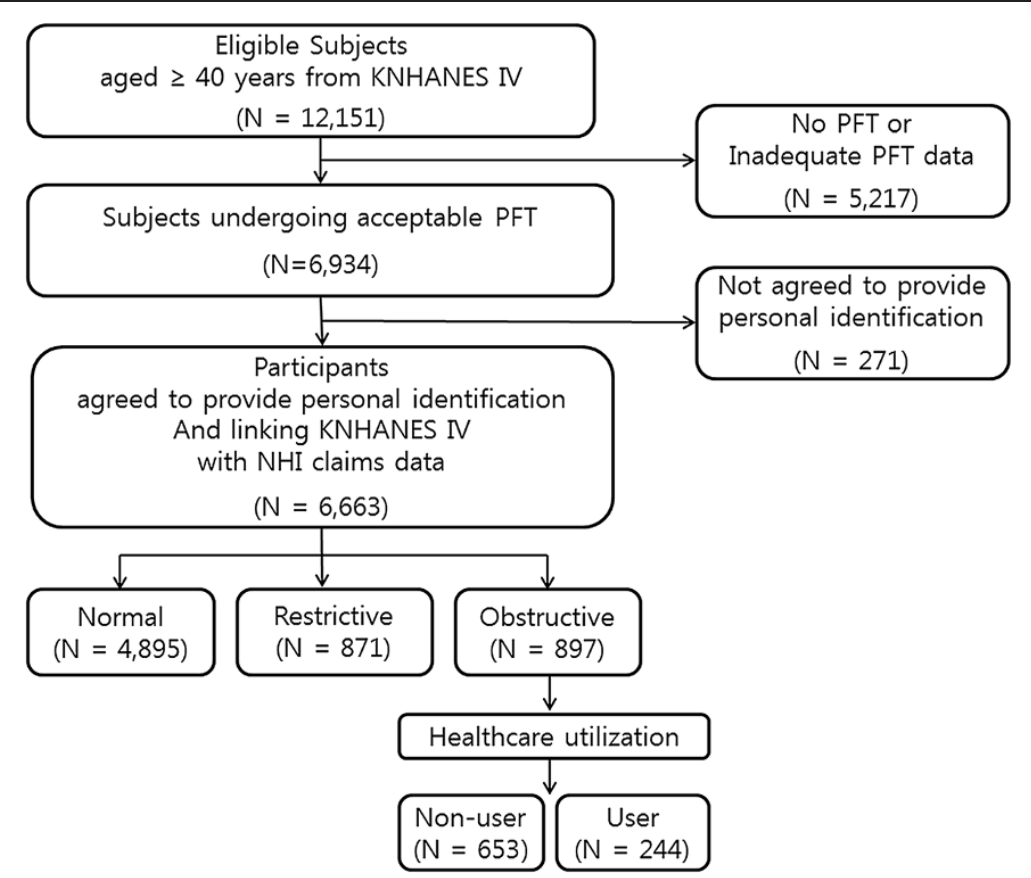

Figure 1 Flow chart for selection of study participants. PFT = pulmonary function test; Normal $=\mathrm{FEV} / \mathrm{FVC} \geq 70 \%$ and $\mathrm{FEV}_{1} \geq 80 \%$ predicted; Restrictive $=\mathrm{FEV}_{1} / \mathrm{FVC} \geq 70 \%$ and $\mathrm{FEV}_{1}<80 \%$ predicted; Obstructive $=\mathrm{FEV}_{1} / \mathrm{FVC}<70 \%$; Non-user $=$ person who did not use healthcare resources at all with first-listed and secondary diagnosis of COPD; User = person who used any kind of healthcare resource with first-listed and secondary diagnosis of COPD.

units, and emergency departments. A user of COPDassociated medication had $>1$ prescription for each drug category per year during the follow-up period. COPDrelated medications were classified as follows: inhaled short-acting $\beta$-agonists (SABA), inhaled short-acting anticholinergics, inhaled long-acting anticholinergics (LAMA), inhaled long-acting $\beta$-agonist combined with corticosteroid (LABA/ICS), inhaled corticosteroid (ICS), oral theophylline, and oral corticosteroid. Several variables were evaluated to identify the determinants of COPD-related healthcare use in bivariate and multivariate analyses. Variables included age, sex, smoking status, residential area, household income, severity of airway obstruction, presence of comorbidities, and self-reported physician diagnosis of COPD.

\section{Statistical analysis}

Data were analyzed using SAS software, version 9.1 (SAS Institute Inc., Cary, NC, USA). Baseline characteristics were summarized using percentages to describe categorical variables, and compared using chi-square analyses. ANOVA was used for analyzing variables associated with healthcare use among subjects classified by severity of airflow obstruction. Determinants of healthcare use between healthcare users and non-users were evaluated by logistic regression analyses, including the following covariates: age, sex, smoking status, residential area, household income, severity of airway obstruction, and physician diagnosis of COPD. Odds ratios were reported with $95 \%$ confidential intervals. A $p$ value of $<0.05$ was regarded as statistically significant.

\section{Results}

\section{Baseline characteristics of study population}

Among 6,663 eligible respondents, 897 (13.5\%) had airway obstruction. Of these patients, $365(40.7 \%)$ were classified as having mild obstruction, $470(52.4 \%)$ with moderate obstruction, and $62(6.9 \%)$ with severe obstruction according to performance on PFTs. COPD was more prevalent in men. Self-reported physician-diagnosed COPD comprised only $3 \%$, and self-reported physician-diagnosed asthma comprised $3.7 \%$ of the 897 subjects (Table 1).

\section{Patterns of healthcare use by severity of airflow obstruction}

Of the 897 respondents, 244 (27.2\%) used COPD-related healthcare services. The frequency of healthcare visits increased with increasing severity of airflow obstruction $(p<0.01)$. Subjects with severe COPD visited healthcare facilities most frequently (Figure 2). Among those patients with airflow limitation $(\mathrm{N}=897)$, there were initially 870 (97\%) undiagnosed COPD patients and 27 (3\%) selfreported physician-diagnosed COPD patients. After the 3-year follow-up period, 74.2\% $(\mathrm{N}=646)$ remained as undiagnosed COPD patients and only $25.8 \%(\mathrm{~N}=224)$ were diagnosed and treated as a COPD, among initially undiagnosed COPD patients $(N=870)$. Seven patients were 

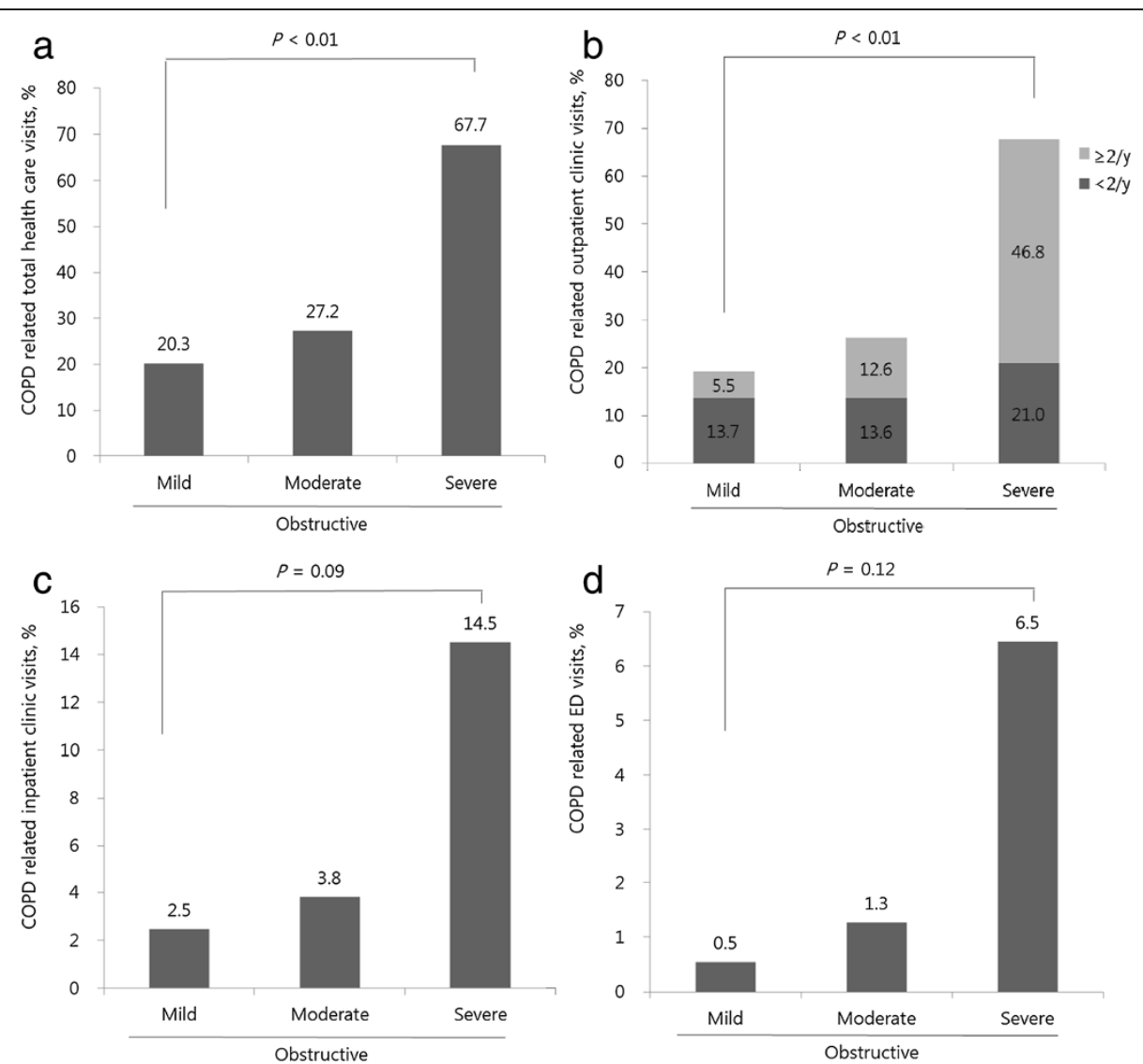

Figure 2 Percentage of COPD-related healthcare visits by severity of airway obstruction. Percentages of COPD related healthcare visits in the mild, moderate, and severe airway obstruction cohort are presented on top of each bar of the graph. Total healthcare visits were divided into outpatient clinic visits, inpatient clinic visits, and emergency department visits. a) COPD-related total healthcare visits, b) COPD-related outpatient

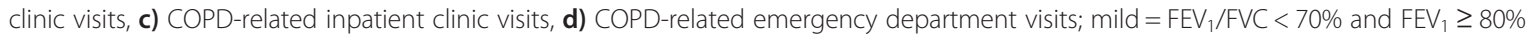
predicted; moderate $=\mathrm{FEV}_{1} / \mathrm{FVC}<70 \%$ and $50 \leq \mathrm{FEV}_{1}<80 \%$ predicted; severe $=\mathrm{FEV}_{1} / \mathrm{FVC}<70 \%$ and $\mathrm{FEV}_{1}<50 \%$ predicted; normal $=\mathrm{FEV} / \mathrm{FVC}$ $\geq 70 \%$ and $\mathrm{FEV}_{1} \geq 80 \%$ predicted; restrictive $=\mathrm{FEV}_{1} / \mathrm{FVC} \geq 70 \%$ and $\mathrm{FEV}_{1}<80 \%$ predicted.

untreated among initially self-reported diagnosed COPD patients $(\mathrm{N}=27)$. Only $27.5 \%$ of the 244 participants with airway obstruction who used COPD-related healthcare underwent PFTs during the study period (data not shown). The percentage of patients undergoing spirometry increased according to the severity of the airflow obstruction $(p=0.03)$ (Figure 3; Table 2).

\section{Patterns of prescribed medications according to the severity of airflow obstruction}

The percentage of prescribed medications associated with COPD increased in accordance with the severity of the COPD. Oral theophylline was prescribed as COPD treatment for $44.6 \%$ of healthcare users, and $21.7 \%$ of users were also prescribed an oral corticosteroid (data not shown). The percentages of prescribed oral theophylline were $33.8 \%$ for mild obstruction, $41.4 \%$ for moderate obstruction, and $73.8 \%$ for severe obstruction (Figure 4; Table 2). SABA was prescribed for $94.6 \%$ of patients with mild airway obstruction, $82 \%$ with moderate obstruction, and $61.9 \%$ with severe obstruction (data not shown). LAMA was prescribed for $10.9 \%$ of patients with moderate airway obstruction and for 52.4\% of patients with severe obstruction. LABA/ICS was prescribed for $50 \%$ of patients with severe airway obstruction (Figure 4).

\section{Bivariate and multivariate determinants of COPD-related healthcare use}

Bivariate and multivariate determinants influencing COPD-related healthcare use are presented in Table 3. Independent variables included in the multivariate logistic analyses were age, sex, smoking status, household income, residential area, severity of airway obstruction, presence of comorbidities, and self-reported physician diagnosis of COPD. The determinants of COPDassociated healthcare use in participants with obstructive lung disease were advanced age, severe airflow limitation, presence of comorbidities, and self-reported physician diagnosis of COPD. 


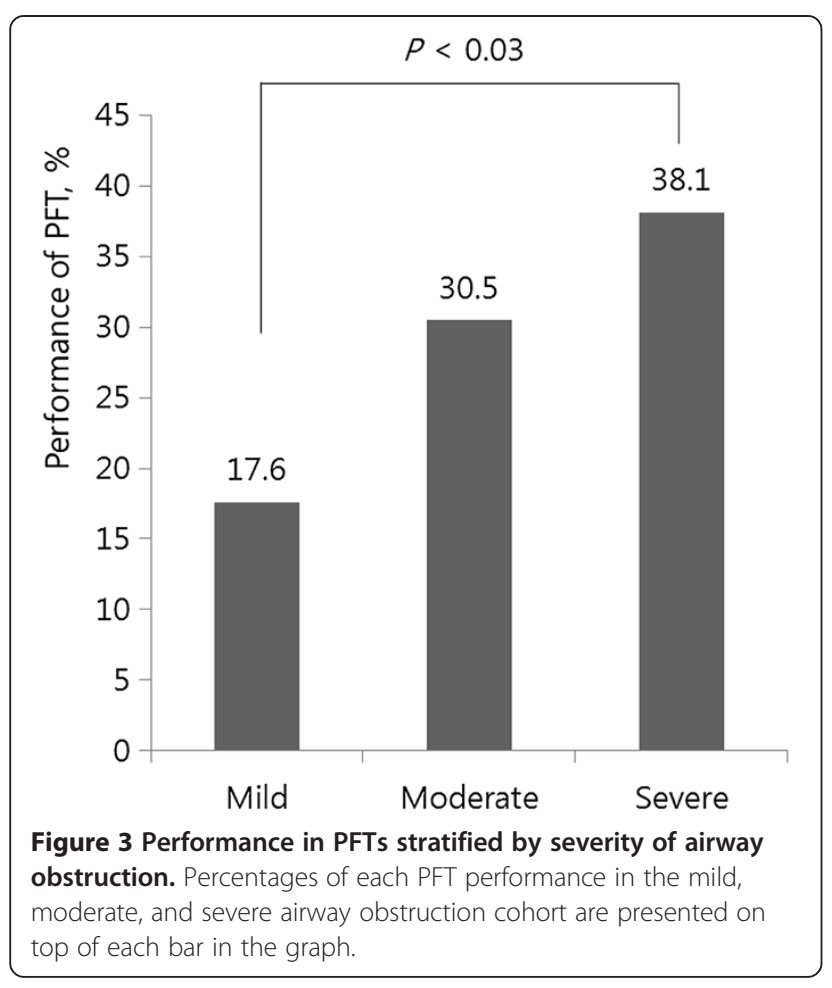

Table 2 Patterns of healthcare visits, PFTs, and prescribed medications according to severity of airflow obstruction

\begin{tabular}{|c|c|c|c|c|}
\hline & $\begin{array}{c}\text { Mild } \\
\text { No. (\%) } \\
74(30.3)\end{array}$ & $\begin{array}{c}\text { Moderate } \\
\text { No. }(\%) \\
128(52.5)\end{array}$ & $\begin{array}{c}\text { Severe } \\
\text { No. (\%) } \\
42(17.2)\end{array}$ & $P$ value \\
\hline \multicolumn{5}{|c|}{ Healthcare visit (frequency/person/year)* } \\
\hline Total & $2.014 \pm 0.323$ & $3.675 \pm 0.473$ & $5.764 \pm 0.783$ & $<0.001$ \\
\hline Outpatient clinic & $1.895 \pm 0.325$ & $3.594 \pm 0.472$ & $5.516 \pm 0.732$ & $<0.001$ \\
\hline Inpatient clinic & $0.118 \pm 0.051$ & $0.082 \pm 0.021$ & $0.248 \pm 0.114$ & 0.091 \\
\hline ICU & $0.025 \pm 0.020$ & $0.005 \pm 0.004$ & $0.039 \pm 0.024$ & 0.219 \\
\hline ED & $0.009 \pm 0.007$ & $0.023 \pm 0.010$ & $0.071 \pm 0.049$ & 0.124 \\
\hline PFT (frequency/person/year)* & $0.109 \pm 0.032$ & $0.168 \pm 0.025$ & $0.263 \pm 0.059$ & 0.031 \\
\hline \multicolumn{5}{|c|}{ Medications (frequency/person/year)* } \\
\hline SABA & $0.050 \pm 0.026$ & $0.287 \pm 0.135$ & $0.957 \pm 0.290$ & 0.003 \\
\hline SAMA & $0.036 \pm 0.023$ & $0.036 \pm 0.015$ & $0.200 \pm 0.104$ & 0.012 \\
\hline LAMA & $0.178 \pm 0.163$ & $0.213 \pm 0.080$ & $1.940 \pm 0.492$ & $<0.001$ \\
\hline$L A B A+I C S$ & $0.054 \pm 0.046$ & $0.408 \pm 0.137$ & $1.280 \pm 0.395$ & $<0.001$ \\
\hline ICS & $0.050 \pm 0.045$ & $0.032 \pm 0.014$ & $0.194 \pm 0.107$ & 0.051 \\
\hline Oral theophylline & $0.484 \pm 0.121$ & $1.156 \pm 0.254$ & $3.162 \pm 0.571$ & $<0.001$ \\
\hline Oral corticosteroid & $0.143 \pm 0.081$ & $0.390 \pm 0.116$ & $1.422 \pm 0.451$ & $<0.001$ \\
\hline
\end{tabular}

${ }^{*}=$ mean \pm standard error; ICU = intensive care unit; ED = emergency department; PFT = pulmonary function test; SABA = inhaled short-acting $\beta$ agonist; SAMA = inhaled short-acting anticholinergic; LAMA = inhaled long-acting anticholinergic; LABA+ICS = inhaled long-acting $\beta$-agonist combined with corticosteroid; ICS = inhaled corticosteroid.

\section{Discussion}

In this study, patterns of healthcare use in subjects with COPD were assessed based on representative, nationwide epidemiological cohort data combined with Korean NHI claims data. The NHI system provides an exact and reliable computerized database for all healthcare service use for the entire population of South Korea. A few epidemiological reports on COPD-related healthcare use exist in the literature [10,13-16]; however, reports on the association between healthcare use patterns and COPD severity are scarce. Our study also identified a total 27.2\% $(\mathrm{N}=244)$ COPD-related healthcare use rate. We observed an increase in use according to disease severity, which was a strong predictor of future healthcare use. However, PFTs were performed in only $27.5 \%$ of patients with COPD. Medications prescribed for COPD in Korea were mainly oral theophylline (44.7\%) and oral corticosteroids (21.7\%), regardless of the disease severity. The major determinants for COPD-related healthcare use were advanced age, disease severity, presence of comorbidities, and physician diagnosis of COPD. These factors should be considered in health plans and in disease management programs for COPD.

The present study showed that total prevalence of COPD based on PFTs was $13.4 \%$. The prevalence of COPD in other countries varies from $7.8 \%$ to $19.7 \%$ [17-19]. In our study, the percentage of self-reported physician-diagnosed COPD was $3 \%(\mathrm{~N}=27)$ and the percentage of PFT-based undiagnosed airway obstruction was $13.1 \% \quad(\mathrm{~N}=870)$. 


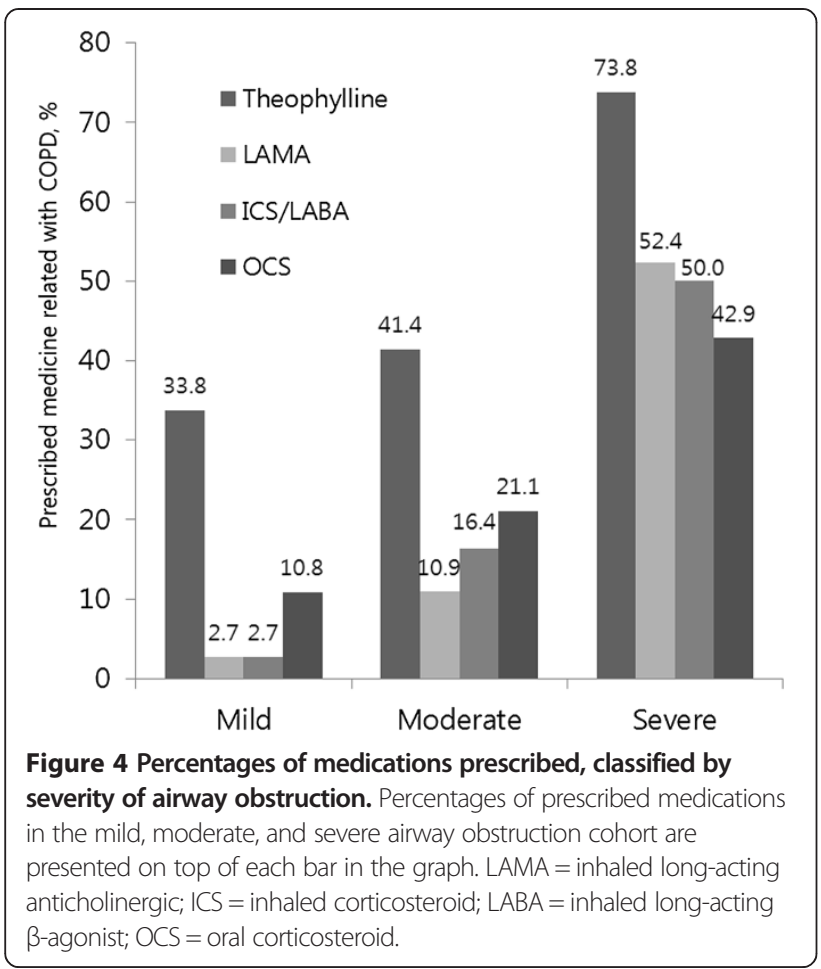

These findings are similar to the U.S. NHANES III study published by Coultas et al. [20], in which the percentage of doctor-diagnosed COPD was $3.1 \%(\mathrm{~N}=179)$ and of undiagnosed airflow obstruction was $12.0 \%(\mathrm{~N}=688)$. Other national data reveal that $<6 \%$ of the adult population has been told by a healthcare provider that they have COPD $[4,6,7,9]$. The reasons for underdiagnosis of COPD include low usage of PFTs [21,22], lack of awareness of COPD, poor physician adherence to guidelines [23], and lack of educational programs on COPD. Asymptomatic COPD patients do not tend to use healthcare services. Most primary care physicians diagnosed COPD based on patients' symptoms and smoking history [21]. Objective diagnosis using PFTs tends to produce higher prevalence estimates than patientreported diagnosis. The underdiagnosis of COPD is likely to result in substantial morbidity and mortality.

The Global Initiative for Chronic Obstructive Lung Disease (GOLD) recommends that PFTs be used for the clinical diagnosis of COPD to avoid underdiagnosis, and to ensure proper evaluation of the severity of the airflow obstruction [4]. Other studies also reported that PFTs were underused in detecting patients with COPD and confirming the diagnosis of COPD [24,25]. Dyspnea, coughing, wheezing, and smoking history are not specific to COPD [24]. PFTs can detect asymptomatic COPD early, which allows for risk factors to be modified (i.e., smoking cessation) [25]. Early detection of COPD is important in Korean men because of that country's high male smoking rate relative to the female smoking rate
(60.6\% vs. $5.2 \%$, respectively) [26]. Han et al. revealed that only $32 \%$ of COPD patients in the United States had PFTs performed within 2 years before, or 6 months after, diagnosis [27]. Our study suggested that the low rate of PFTs performed (27.5\%) might be associated with the underdiagnosis of COPD in Korea.

Interestingly, the percentages of prescribed oral theophylline $(44.6 \%)$ and oral corticosteroids (21.7\%) were high regardless of the severity of airflow obstruction in our study (data not shown). The high prescribing rate of oral theophylline may be associated with patients' preference for oral medications in Korea. The low prescribing rate of LAMA and LABA/ICS may be related to underdiagnosis of COPD. The GOLD guidelines clearly outline which classes of COPD medications should be prescribed according to disease severity. A few reports demonstrate that COPD treatment guidelines reduce healthcare use and mortality [28]. Nevertheless, physician adherence to prescribing guidelines and patient adherence to drug therapy remain poor $[10,29]$. The COPD Resource Network Needs Assessment Survey reported that $54 \%$ of primary physicians and $94 \%$ of pulmonologists under-prescribed recommended pharmacological treatments despite acknowledging awareness of the current COPD treatment guidelines [30]. Park et al. showed that $56.7 \%$ of primary care physicians in Korea knew about the GOLD guidelines and $61.8 \%$ had spirometry equipment. However, PFTs were often underused because of problems with spirometry equipment, refusal by patients, and unawareness of the importance of screening patients for COPD. Common respiratory medications prescribed for stable COPD included oral theophylline (24.9\%), inhaled anticholinergics (22.1\%), oral $\beta 2$-agonists (17.1\%), and inhaled $\beta 2$ agonists (15.7\%), which was consistent with our results [31].

Our study revealed that the severity of the airflow obstruction was one of the major determinants of COPDrelated healthcare use. Some authors have suggested that comorbidities or symptoms were more relevant determinants than the severity of the airway obstruction in determining healthcare use [16,32-34]. Other authors showed that the severity of COPD was strongly correlated with healthcare use $[29,35]$. In our study, subjects with moderate and severe airway obstruction used healthcare services more frequently than patients with mild obstruction. Additionally, in our study, age and comorbidities were also identified as determinants of COPD-related healthcare use [32]. Unlike other studies, household income [15] and smoking status [16] were not related to healthcare use. In this study, self-reported physician-diagnosed COPD was also a major determinant of healthcare use. Lack of knowledge about COPD may affect the use of healthcare, but further study is needed. However, we did not include acute exacerbation events with the classical criteria of acute exacerbation. 
Table 3 Bivariate and multivariate determinants of COPD-related healthcare use

\begin{tabular}{|c|c|c|c|c|c|}
\hline \multirow[t]{4}{*}{ Variables } & \multicolumn{2}{|c|}{ COPD-related healthcare utilization } & \multirow[b]{4}{*}{ OR } & \multirow[b]{4}{*}{$95 \% \mathrm{Cl}$} & \multirow[b]{4}{*}{$P$ value } \\
\hline & User & Non-user & & & \\
\hline & No. (\%) & No. (\%) & & & \\
\hline & $244(27.2)$ & $653(72.8)$ & & & \\
\hline \multicolumn{6}{|l|}{ Age (yr) } \\
\hline $40 \sim 59$ & $50(19.2)$ & $211(80.8)$ & 1.00 & & \\
\hline$\geq 60$ & $194(30.5)$ & $442(69.5)$ & 1.56 & $1.03-2.36$ & 0.04 \\
\hline \multicolumn{6}{|l|}{ Sex } \\
\hline Female & $74(27.5)$ & $195(72.5)$ & 1.00 & & \\
\hline Male & $170(27.1)$ & $458(72.9)$ & 1.13 & $0.71-1.77$ & 0.61 \\
\hline \multicolumn{6}{|l|}{ Smoking status } \\
\hline Never & $75(25.7)$ & $217(74.3)$ & 1.00 & & \\
\hline Former & $82(27.4)$ & $217(72.6)$ & 1.04 & $0.63-1.70$ & 0.89 \\
\hline Current $\S$ & $87(28.9)$ & $214(71.1)$ & 1.32 & $0.82-2.13$ & 0.26 \\
\hline \multicolumn{6}{|l|}{ Residential area } \\
\hline Urban & $138(25.9)$ & $394(74.1)$ & 1.00 & & \\
\hline Rural & $106(29.0)$ & $259(71.0)$ & 1.07 & $0.78-1.48$ & 0.68 \\
\hline \multicolumn{6}{|l|}{ Household income } \\
\hline$\geq$ Lower quartile & $129(23.5)$ & $421(76.6)$ & 1.00 & & \\
\hline$<$ Lower quartile & $115(33.1)$ & $232(66.9)$ & 1.32 & $0.94-1.85$ & 0.10 \\
\hline \multicolumn{6}{|c|}{ Severity of airway obstruction } \\
\hline Mild & $74(20.3)$ & $291(79.7)$ & 1.00 & & \\
\hline Moderate & $128(27.2)$ & $342(72.8)$ & 1.54 & $1.10-2.15$ & 0.01 \\
\hline Severeף & $42(67.7)$ & $20(32.3)$ & 6.68 & $3.60-12.38$ & $<0.01$ \\
\hline \multicolumn{6}{|c|}{ No. of co-morbidities } \\
\hline 0 & $107(22.4)$ & $370(77.6)$ & 1.00 & & \\
\hline$\geq 1$ & $137(32.6)$ & $283(67.4)$ & 1.44 & $1.03-2.01$ & 0.03 \\
\hline \multicolumn{6}{|c|}{ Self-reported physician diagnosis of COPD } \\
\hline No & $224(25.8)$ & $646(74.3)$ & 1.00 & & \\
\hline Yes & $20(74.1)$ & $7(25.9)$ & 5.30 & $2.08-13.54$ & $<0.01$ \\
\hline
\end{tabular}

In those criteria, acute exacerbation is defined by an acute event characterized by a worsening of the patient's respiratory symptoms that is beyond normal day-to-day variations, and leads to a change in medication. In most studies concerned with acute exacerbation of COPD, moderate to severe exacerbation of COPD is defined by an emergency room visit or admission due to COPD. We analyzed data regarding COPD-related admissions to hospital and visits to emergency departments, which can be considered as involving moderate to severe exacerbation of COPD.

There are several limitations to our study. First, the follow-up period was only 1-3 years. Second, results from this study cannot be generalized to the entire Korean population over 40 years of age. Participants in this study might have been relatively healthy, while sedentary patients with severe airway obstruction might not have been included in our study. Thus, we cannot entirely rule out selection bias. In addition, healthcare users comprised a small sample size. Further studies need a larger, nationwide sample with a much longer follow-up period. Third, eligible participants were selected using a fixed $\mathrm{FEV}_{1} / \mathrm{FVC}$ ratio, and airflow obstruction was determined without consideration of the decrease in pulmonary function that occurs with age. COPD among the elderly in our study seemed overrepresented [36]. Furthermore, lung function data from this study were based on pre-bronchodilator PFTs, and the inadvertent inclusion of asthma patients might have skewed the results. In addition, in the survey questionnaire, we had questions regarding self-reported physician diagnosis of asthma. In doing so, we were trying to 
exclude asthma patients, but it is not possible to do this using self-reported physician diagnosis criteria. It is a limitation of nationwide surveys, and it is not possible to differentiate COPD patients from asthma patients in the KNHANES study. We could not exclude from this study population asthma patients older than 40 years of age who had airflow limitation. As a result, we analyzed patterns and determinants of healthcare use in patients with airway obstruction, which might have included cases with COPD or bronchial asthma. We tried to clarify data from COPD-related ICD-10 codes in NHI claims during the 3-year follow-up period. Therefore, the number of patients who did not use healthcare resources might have included cases with COPD or asthma. Fourth, identification of patients based on insurance claims data also relies on the correct use and input of codes into the computerized insurance database. It would have been useful to have data regarding nonpharmacological interventions such as smoking cessation, physical activity, rehabilitation, and vaccination. Unfortunately, we could not extract information about non-pharmacological interventions using COPD-related claims codes from the NHI claims data, because nonpharmacological interventions are not covered and reimbursed by the NHI system in Korea. This is also a limitation. Last, we could not analyze data about respiratory symptoms because major questions about such symptoms were not included in the survey questionnaire. We accept that the absence of analysis regarding respiratory symptoms is a flaw. These factors could influence major determinants of healthcare use [16]. There is still debate about the use of spirometry vs. symptom questionnaires [37] in the screening and diagnosis of COPD. Future studies should analyze the severity of airflow obstruction with well-established lung function questionnaires.

\section{Conclusions}

Among patients with COPD, 27.2\% used COPD-related healthcare services. Only $27.5 \%$ of the 244 participants with airway obstruction who used COPD-related healthcare underwent PFTs. The percentage of prescribed medications associated with COPD increased in accordance with the severity of the COPD. However, oral theophylline and oral corticosteroids were mainly prescribed. The determinants of COPD-associated healthcare use in subjects with obstructive lung disease were advanced age, severe airflow limitation, presence of comorbidities, and self-reported physician diagnosis of COPD.

\footnotetext{
Abbreviations

KNHANES: Korean National Health and Nutritional Examination Survey; $\mathrm{NHI}$ : National health insurance; COPD: Chronic obstructive pulmonary disease; PFT: Pulmonary function test; SABA: Inhaled short-acting $\beta$-agonist; LAMA: Inhaled long-acting anticholinergic; LABA/ICS: Inhaled long-acting $\beta$-agonist combined with corticosteroid; ICS: Inhaled corticosteroid.
}

\section{Competing interests}

The authors declare that they have no competing interests.

\section{Authors' contributions}

$K C$, JK, and YK contributed to the study design, data analysis and interpretation, and writing of this manuscript. KK, JJ, KO, YO, and SK contributed to the study design, data analysis and interpretation, and review of this manuscript. JK and YK contributed equally to this article. All authors read and approved the final manuscript.

\section{Funding}

This study was supported by a grant of the Korea Healthcare Technology R\&D Project, Ministry for Health and Welfare, Republic of Korea. (HI10C2020).

\section{Author details}

'Division of Pulmonology, Department of Internal Medicine, The Institute of Chest Disease, Severance Hospital, Yonsei University College of Medicine, Seoul, Republic of Korea. ${ }^{2}$ Yuhan Research Institute, Yongin, Gyeonggi-do, Republic of Korea. ${ }^{3}$ Division of Health and Nutrition Survey, Korea Centers for Disease Control and Prevention, Osong, Chungcheongbuk-do, Republic of Korea. ${ }^{4}$ Department of Pulmonary and Critical Care Medicine, and Asthma Center, Asan Medical Center, University of Ulsan College of Medicine, Seoul, Republic of Korea. ${ }^{5}$ Department of Nursing, College of Medicine, Chosun University, Gwangju, Republic of Korea.

Received: 8 March 2013 Accepted: 19 February 2014

Published: 27 February 2014

\section{References}

1. Decramer M, Janssens W, Miravitlles M: Chronic obstructive pulmonary disease. Lancet 2012, 379(9823):1341-1351.

2. Mannino DM, Buist AS: Global burden of COPD: risk factors, prevalence, and future trends. Lancet 2007, 370(9589):765-773.

3. Tan WC, Ng TP: COPD in Asia: where East meets West. Chest 2008, 133(2):517-527.

4. Vestbo J, Hurd SS, Agustí AG, Jones PW, Vogelmeier C, Anzueto A, Barnes PJ, Fabbri LM, Martinez FJ, Nishimura M, Stockley RA, Sin DD, RodriguezRoisin R: Global strategy for the diagnosis, management and prevention of chronic obstructive pulmonary disease, GOLD executive summary. Am J Respir Crit Care Med 2012, 187(4):347-365.

5. Bednarek M, Maciejewski J, Wozniak M, Kuca P, Zielinski J: Prevalence, severity and underdiagnosis of COPD in the primary care setting. Thorax 2008, 63(5):402-407.

6. Soriano JB, Maier WC, Egger P, Visick G, Thakrar B, Sykes J, Pride NB: Recent trends in physician diagnosed COPD in women and men in the UK. Thorax 2000, 55(9):789-794.

7. Chapman KR: Chronic obstructive pulmonary disease: are women more susceptible than men? Clin Chest Med 2004, 25(2):331-341.

8. Pena VS, Miravitlles M, Gabriel R, Jimenez-Ruiz CA, Villasante C, Masa JF, Viejo JL, Fernandez-Fau L: Geographic variations in prevalence and underdiagnosis of COPD: results of the IBERPOC multicentre epidemiological study. Chest 2000, 118(4):981-989.

9. Centers for Disease C, Prevention: Chronic obstructive pulmonary disease and associated health-care resource use - North Carolina, 2007 and 2009. MMWR 2012, 61(8):143-146.

10. Fitch K, Iwasaki K, Pyenson B, Plauschinat C, Zhang J: Variation in adherence with global initiative for chronic obstructive lung disease (GOLD) drug therapy guidelines: a retrospective actuarial claims data analysis. Curr Med Res Opin 2011, 27(7):1425-1429.

11. Joo MJ, Lee TA, Bartle B, van de Graaff WB, Weiss KB: Patterns of healthcare utilization by COPD severity: a pilot study. Lung 2008, 186(5):307-312.

12. Pellegrino R, Viegi G, Brusasco V, Crapo RO, Burgos F, Casaburi R, Coates A, van der Grinten CP, Gustafsson P, Hankinson J, Jensen R, Johnson DC, Maclntyre N, McKay R, Miller MR, Navajas D, Pedersen OF, Wanger J: Interpretative strategies for lung function tests. Eur Respir J 2005, 26(5):948-968.

13. Mapel DW, Dutro MP, Marton JP, Woodruff K, Make B: Identifying and characterizing COPD patients in US managed care. A retrospective, cross-sectional analysis of administrative claims data. BMC Health Serv Res 2011, 11:43. 
14. Blanchette CM, Broder M, Ory C, Chang E, Akazawa M, Dalal AA: Cost and utilization of COPD and asthma among insured adults in the US. Curr Med Res Opin 2009, 25(6):1385-1392.

15. Jung JY, Kang YA, Park MS, Oh YM, Park EC, Kim HR, Lee SD, Kim SK, Chang J, Kim YS: Chronic obstructive lung disease-related health care utilisation in Korean adults with obstructive lung disease. Int J Tuberc Lung Dis 2011, 15(6):824-829.

16. Mapel DW, McMillan GP, Frost FJ, Hurley JS, Picchi MA, Lydick E, Spencer MD: Predicting the costs of managing patients with chronic obstructive pulmonary disease. Resp Med 2005, 99(10):1325-1333.

17. Halbert RJ, Natoli JL, Gano A, Badamgarav E, Buist AS, Mannino DM: Global burden of COPD: systematic review and meta-analysis. Eur Respir J 2006, 28(3):523-532.

18. Menezes AM, Perez-Padilla R, Jardim JR, Muino A, Lopez MV, Valdivia G, de Oca Montes M, Talamo C, Hallal PC, Victora CG, PLATINO Team: Chronic obstructive pulmonary disease in five Latin American cities (the PLATINO study): a prevalence study. Lancet 2005, 366(9500):1875-1881.

19. Buist AS, McBurnie MA, Vollmer WM, Gillespie S, Burney P, Mannino DM, Menezes AM, Sullivan SD, Lee TA, Weiss KB, Jensen RL, Marks GB, Gulsvik A, Nizankowska-Moqilnicka E, BOLD Collaborative Research Group: International variation in the prevalence of COPD (the BOLD Study): a population-based prevalence study. Lancet 2007, 370(9589):741-750.

20. Coultas DB, Mapel D, Gagnon R, Lydick E: The health impact of undiagnosed airflow obstruction in a national sample of United States adults. Am J Respir Crit Care Med 2001, 164(3):372-377.

21. Glaab T, Banik N, Rutschmann OT, Wencker M: National survey of guideline-compliant COPD management among pneumologists and primary care physicians. Copd 2006, 3(3):141-148.

22. Decramer M, Bartsch P, Pauwels R, Yernault JC: Management of COPD according to guidelines. A national survey among Belgian physicians. Monaldi Arch Chest Dis 2003, 59(1):62-80.

23. Cooke CE, Sidel M, Belletti DA, Fuhlbrigge AL: Review: clinical inertia in the management of chronic obstructive pulmonary disease. Copd 2012, 9(1):73-80.

24. Mapel DW, Picchi MA, Hurley JS, Frost FJ, Petersen HV, Mapel VM, Coultas DB: Utilization in COPD: patient characteristics and diagnostic evaluation. Chest 2000, 117(5 Suppl 2):346S-353S.

25. Soriano JB, Zielinski J, Price D: Screening for and early detection of chronic obstructive pulmonary disease. Lancet 2009, 374(9691):721-732.

26. Kim DS, Kim YS, Jung KS, Chang JH, Lim CM, Lee JH, Uh ST, Shim JJ, Lew WJ, Korean Academy of Tuberculosis and Respiratory Diseases: Prevalence of chronic obstructive pulmonary disease in Korea: a population-based spirometry survey. Am J Respir Crit Care Med 2005, 172(7):842-847.

27. Han MK, Kim MG, Mardon R, Renner P, Sullivan S, Diette GB, Martinez FJ: Spirometry utilization for COPD: how do we measure up? Chest 2007, 132(2):403-409.

28. Heffner JE, Ellis R: The guideline approach to chronic obstructive pulmonary disease: how effective? Respir Care 2003, 48(12):1257-1266. discussion 1267-1258.

29. Seaman J, Leonard AC, Panos RJ: Health care utilization history, GOLD guidelines, and respiratory medication prescriptions in patients with COPD. Int J Chron Obstruct Pulmon Dis 2010, 5:89-97.

30. Barr RG, Celli BR, Martinez FJ, Ries AL, Rennard SI, Reilly JJ Jr, Sciurba FC, Thomashow BM, Wise RA: Physician and patient perceptions in COPD: the COPD resource network needs assessment survey. Am J Med 2005, 118(12):1415.

31. Park MJ, Choi CW, Kim SJ, Kim YK, Lee SY, Kang KH, Shin KC, Lee KH, Lee JH, Kim YI, Lim SC, Park YB, Jung KS, Kim TH, Shin DH, Yoo JH: Survey of COPD management among the primary care physicians in Korea. Tuberc Respir Dis 2008, 64(2):109-124.

32. Simon-Tuval T, Scharf SM, Maimon N, Bernhard-Scharf BJ, Reuveni $H$, Tarasiuk A: Determinants of elevated healthcare utilization in patients with COPD. Respir Res 2011, 12:7.

33. Vestbo J, Rasmussen FV: Respiratory symptoms and FEV1 as predictors of hospitalization and medication in the following 12 years due to respiratory disease. Eur Respir J 1989, 2(8):710-715

34. O'Reilly JF, Williams AE, Holt K, Rice L: Defining COPD exacerbations: impact on estimation of incidence and burden in primary care. Prim Care Respir J 2006, 15(6):346-353.

35. Hilleman DE, Dewan N, Malesker M, Friedman M: Pharmacoeconomic evaluation of COPD. Chest 2000, 118(5):1278-1285.
36. Hardie JA, Buist AS, Vollmer WM, Ellingsen I, Bakke PS, Morkve O: Risk of over-diagnosis of COPD in asymptomatic elderly never-smokers. Eur Respir J 2002, 20(5):1117-1122.

37. Hanania NA, Mannino DM, Yawn BP, Mapel DW, Martinez FJ, Donohue JF, Kosinski M, Rendas-Baum R, Mintz M, Samuels S, Jhingran P, Dalal AA: Predicting risk of airflow obstruction in primary care: validation of the lung function questionnaire (LFQ). Resp Med 2010, 104(8):1160-1170.

doi:10.1186/1471-2466-14-27

Cite this article as: Chung et al:: Patterns and determinants of COPDrelated healthcare utilization by severity of airway obstruction in Korea. BMC Pulmonary Medicine 2014 14:27.

\section{Submit your next manuscript to BioMed Central and take full advantage of:}

- Convenient online submission

- Thorough peer review

- No space constraints or color figure charges

- Immediate publication on acceptance

- Inclusion in PubMed, CAS, Scopus and Google Scholar

- Research which is freely available for redistribution

Submit your manuscript at www.biomedcentral.com/submit
C Biomed Central 